\title{
LAS REFORMAS ADMINISTRATIVAS PARA EL TRATAMIENTO DE LA LEPRA EN LA SEGUNDA MITAD DEL SIGLO XVIII
}

\author{
Jorge Tomás Uribe Angel \\ Instituto Colombiano de Cultura Hispánica
}

Los principales problemas de salud pública que afrontaba el virreinato de la Nueva Granada eran, según lo reconocían las propias autoridades, los relativos a la viruela y a la lepra. A pesar de que esta última, enfermedad de lento desarrollo que sólo se manifestaba en un sector muy reducido de la población, no alcanzaba las dimensiones catastróficas y repentinas de las viruelas, despertaba sentimientos de miedo y de repulsa que contribuyeron por una parte, a reforzar el imaginario en virtud del cual, los leprosos debían vivir separados del cuerpo social, y por la otra a que el sector institucional tomara medidas con base en el carácter contagioso que se le atribuía a la enfermedad. Ese carácter contagioso fue el que estimuló a las autoridades a aislar el grupo leproso, a través de una serie de medidas, como paite del tratamiento de tipo institucional que recibió ese núcleo a partir de 1750 , fecha que señala la presencia de una documentación relativamente 
numerosa sobre el particular y fecha, también, a partir de la cual se empezó a crear el ambiente propicio para la introducción de esas medidas, cuyo análisis es el objeto de este artículo.

Todavía no se ha publicado un texto que desarrolle, como tema principal, la lepra en la Colonia. No vamos a inquirir las razones que explican esa omisión. y que sin lugar a dudas, obedecen a que solamente en época reciente han cobrado interés los estudios relativos a la salud en este periodo, y a que, concretamente en el caso de la lepra, ésta no constituye ya un problema de las dimensiones que presentó hasta mediados del presente siglo. Si bien en la actualidad la enfermedad no ha sido erradicada, existen otros flagelos que para la ciencia médica y para la opinión en general, despiertan mayor atención.

Los pocos trabajos que se han elaborado sobre la incidencia de la lepra en la época colonial han abordado la enfermedad desde el punto de vista médico, ${ }^{1}$ sociológico $^{2}$ o regional, ${ }^{3}$ especialmente. Recientemente, han cobrado importancia los estudios históricos sobre la lepra en el período republicano. ${ }^{4}$

1 Por haber sido escrito en la época en que todavía conservaba una marcada importancia dentro de la salud pública, el autor cuyo texto ha estudiado más ampliamente los lazarinos en la Colonia sigue siendo Juan Bautista Montoya y Florez, quien en su Contribución al estudio de la lepra en Colombia, Medellín. Imprenta Editorial, 1910, se apoya en las fuentes primarias encontradas en el fondo Lazaretos del hoy Archivo General de la Nación. Se han escrito, desde el punto de vista médico, además, artículos como el de Tomás Morales Muñoz, Mario Berna! L. y H. C. De Souza Araújo "La lepra en Colombia", Encuestas epidemiológicas, Bogotá, 1940, en el capítulo titulado "Lazareto de Caño de Loro, Cartagena", en el cual se insertan algunos datos, sin precisar las fuentes, acerca del citado centro hospitalario.

2 Sobre el particular hay un estudio no publicado de Renán Silva, "La enfermedad de Hansen y la elefancía"'. Centro Universitario de Ciencias Sociales y Salud, Ceucsa, Universidad del Valle, 1992. Este texto sirvió de base para las referencias históricas contenidas en el ensayo de Elias Sevilla Casas, sobre la enfermedad en Colombia en la actualidad, titulado "Los mutilados del oprobio", Colcultura, 1994.

3 De Horacio Rodríguez Plata es un artículo, "Origen de la lepra en la antigua Provincia del Socorro", publicado en el Boletín de Historia y Antiguedades Nos. 751-754, 1987. El trabajo, encontrado entre los papeles postumos del autor, fue escrito en 1935, y se refiere, en cinco páginas, al supuesto origen de la enfermedad en su tierra natal. El Socorro, y las visitas efectuadas por profesionales de la medicina con el fin de practicar la diligencia de reconocimiento de la dolencia.

4 Sobre el particular, la historiadora Diana Obregón Torres ha publicado artículos como "Lepra, 1997" y "De árbol maldito' a 'enfermedad curable: exageración y autoridad médica", ponencia presentada en el $10^{\circ}$ Congreso de Historia de Colombia, Medellín; "Los médicos y la construcción de la lepra en Colombia. 1884-1939", Salud, Sociedad y Cultura en América Latina: nuevas perspectivas históricas. Lima, Instituto de Estudios Peruanos, 1996, pp. 159-178. La tesis doctoral de la historiadora Obregón es "Struggling against Leprosy: Physicians, Medicine and Society in Colombia 1880-1940", Virginia Polytechnic Institute \& State University, 1997. En otro artículo de esta autora, "Medicalización de la lepra, una estrategia nacional", Anuario Colombiano de Historia Social y de la Cultura, Nro. 24, 1997, pp. 139-167, se menciona que a principios del siglo XX, las estrategias para combatir el flagelo se basaban principalmente en la medicalización -la enfermedad debía ser reconocida por un facultativo- en la centralización de los órganos encargados de controlarla y en el aislamiento de los enfermos. 


\section{LAS REFORMAS BORBONICAS EN LA NUEVA GRANADA}

El presente artículo busca destacar las medidas institucionales que entre $1750 \mathrm{y}$ 1810 se dictaron con relación a la enfermedad y las repercusiones que tuvieron estas medidas, en el tratamiento que se le otorgó. Así mismo, con este texto se pretende destacar la trayectoria que siguieron estas disposiciones al ser mediadas por los intereses locales, que se pusieron en juego con el eventual propósito de disputar a la entidad destinada por la Corona al tratamiento de la lepra, el hospital de San Lázaro de Cartagena, su carácter de ser el único centro habilitado para atender la dolencia.

Las reformas borbónicas no rindieron en la Nueva Granada los resultados esperados por las autoridades españolas. En realidad, si se comparan los planes y proyectos presentados con los resultados obtenidos, el balance, en términos de los beneficios buscados por la Corona, no es alentador, aunque a nivel de cada reforma y de su influjo en cada uno de las regiones que comprendía el virreinato, por lo menos, es necesario hacer evaluaciones más detalladas.

Antes de abordar el examen de esas reformas, es importante detenernos en la estructura administrativa vigente antes de la creación del virreinato. Hasta ese entonces, el territorio que luego estaría bajo su jurisdicción comprendía varias Audiencias, siendo las más importantes las de Santafé y Quito. Estos organismos tenían amplias competencias con respecto al funcionamiento de algunos ramos de la administración, por ejemplo en el aspecto jurisdiccional y propiamente administrativo, pero no en otros, como en lo relativo a la Real Hacienda y al campo militar. A pesar de que, a nivel del virreinato del Peni, cada Audiencia gozaba de amplia autonomía, las atribuciones de quien las dirigía, el presidente, eran limitadas en relación con las que llegaron a poseer los virreyes. El hecho de que en un solo virreinato, por ejemplo el de la Nueva Granada, pudieran actuar varias Audiencias, fue definitivo en el modo como se manejaron administrativamente ciertos asuntos, como los relativos a la lepra.

Por lo pronto, hay que aclarar que en el virreinato de la Nueva Granada, -cuya primera etapa empezó a funcionar en 1719- no se introdujeron todas las reformas que se adoptaron para el resto de las colonias. El sistema de intendencias, el principal instrumento administrativo de la nueva política, y cuyos titulares gozaban 
de facultades que les permitían actuar con independencia de virreyes y oidores, "por circunstancias que aún no han sido aclaradas" ${ }^{5}$ no fue implantado en la Nueva Granada. En su lugar se creó la institución de la Regencia, con competencias similares a las de la intendencia. Sin embargo, con excepción de Juan Francisco Gutiérrez de Piñeres, cuya actuación- comprendida entre 1778 y 1793- en procura de nuevos tributos precipitó, como se sabe, la Revolución de los Comuneros, la gestión de los sucesivos regentes tuvo poca significación en el virreinato; inclusive entre 1799 y 1810 el cargo permaneció acéfalo.

En el campo económico, la aplicación del "Reglamento de libre comercio" de 1778, destinado a sustraer esa actividad de los lincamientos del mercantilismo, sólo empezó a producir efectos notorios a partir de 1785, cuando se presentó un aumento moderado de las exportaciones distintas al oro, tales como algodón, cueros, cacao y quina. Los resultados obtenidos, en relación con los de otras colonias, fueron desfavorables. ${ }^{6}$ "Despite the promulgation of 'free trade'in 1778. an accomodation to bring the colony into a satisfactory, workable relationship with the mother country never emerged". ${ }^{7}$

En relación con la educación, a pesar de los evidentes avances que significaron la Expedición Botánica, las investigaciones en técnicas de minería, el Observatorio Astronómico, la creación del "Papel Periódico de Santafé de Bogotá" y el plan de Moreno y Escandón relativo a la universidad pública, la enseñanza en los colegios mayores volvió a los métodos y contenidos tradicionales. En cuanto a las reformas militares, ${ }^{8}$ si consiguieron alguna aceptación en las costas, no ocurrió lo propio en el interior del país donde, en general, las élites locales no les prestaron el apoyo necesario. En el campo social, ${ }^{9}$ las reformas introducidas, en lugar de empezar a

\footnotetext{
5 Jaime Jaramillo Uribc, "La administración colonial", Nueva Historia de Colombia, Bogotá, Planeta Vol. 1, 1989, p. 85.

6 John R. Fischer, "The effects of comercio libre on the economies of New Granada and Perú: Í comparison", 45 Congreso Internacional de Americanistas, Bogotá. Uniandes, pp 45-67.

7 Alian J. Kuethe, "The early reforms of Charles III in the New Granada", 45 Congreso Internacional de Americanistas. Bogotá. Uniandes. p. 80.

8 Alian J. Kuethe. Reformar militar y sociedad en ;a Nueva Granada 1773-1808, Bogotá, Coleccición Bibliográfica del Banco de la República. 1993.

9 Ver Ann Twinam, "Las reformas sociales de los Borbones: una interpretacion revisionista", ponencia presentada en el Congreso de Historia de 1997, Medellín.
} 
desmontar el sistema de castas, lo fortalecieron. La Real Pragmática de 1776, sobre matrimonios, permitió que los padres se opusieran al matrimonio de sus hijos menores de 25 años por razones de tipo racial, social y económico. Las otras reformas sociales, las de las "gracias al sacar' a favor de los hijos ilegítimos (1795) y de los miembros de las castas (1795) y la que equiparaba los expósitos a los ilegítimos (1794) tuvieron escasa aplicación de parte de las autoridades.

Dentro de las reformas borbónicas, no están incluidas explícitamente las medidas institucionales que son objeto de este estudio, pero es evidente que compartieron su espíritu centralizador y tanto las unas como las otras estuvieron influenciadas por la Ilustración en su versión española. Dentro del espíritu ilustrado, la salud pública ocupaba un lugar especial por cuanto se consideraba que era función del gobernante velar por la felicidad del cuerpo social llevando a cabo las medidas que estuvieran a su alcance, y que se encaminaran no sólo a proteger a los sanos, sino a procurar la curación de la enfermedad. Todo ello dentro de una concepción filantrópica que exaltaba el amor a la humanidad como uno de los valores más excelsos.

\section{EL ESCENARIO INSTITUCIONAL}

El escenario de orden institucional fue, por antonomasia, el hospital de San Lázaro de Cartagena. Posteriormente, a lo largo de la segunda mitad del siglo XVIII, la institución fue perdiendo su carácter de exclusividad para la atención de los leprosos, en la medida en que se dio cabida a las pretensiones locales que se expresaron a través de las solicitudes de erección de nuevos hospitales y de la puesta en marcha de las autorizaciones respectivas.

El hospital de San Lázaro, destinado a servir de albergue a los leprosos, al parecer se fundó en 1608, por orden de Felipe IV, bajo la presidencia de don Juan de Borja y por disposición del Cabildo de Cartagena, ${ }^{10} \mathrm{y}$ fue uno de los leprocomios más antiguos de los territorios españoles en América. Aproximadamente por esa fecha, se estableció un leprocomio en La Habana.

\footnotetext{
10 Dato aparecido en Elias Sevilla Casas. Los mutilados del oprobio. Estudios sobre Ja lepra en una región endémica de Colombia. Santafé de Bogotá. Colcultura, 1995. p. 52. "'La lepra en Colombia", Encuestas epidemiológicas, en el capítulo titulado "Lazareto de Caño de Loro", p. 6 de Tomás Morales Muñoz. Mario Bernal Londoño y H. C. de Souza Araujo, y que los autores atribuyen a Eduardo Gutiérrez de Piñeres, se dice que el hospital se fundó entre 1608 y 1610.
} 
Se afirma ${ }^{11}$ que estuvo al principio cerca de la plaza de Cartagena, pero que, por quejas de ios vecinos, fue retirado a las afueras de la ciudad, sobre la colina o monte de su nombre, cerca del fuerte de San Felipe de Barajas, que Fidel J. Pérez Calvo ${ }^{12}$ sitúa "entre el camino de Cartagena ai pie de La Popa y el caño de Basurto y entre el camino que conduce a Manga y un playón". Por entonces estaba conformado por varias chozas pajizas, unidades separadas como los lazaretos de la Edad Media, estructura que conservó a través de las distintas versiones que tuvo el hospital tanto en su sede cartagenera como en Caño de Loro.

San Pedro Claver, en 1615, se percató de las deficiencias físicas de la estructura. y a instancias suyas, en 1620, el capitán Diego de la Torre cercó de tapias el lazareto e hizo reconstruir la capilla, con materiales de construcción consistentes, distintos a la paja con la cual se levantaban las chozas donde habitaban los enfermos.

Este mismo aspecto debió haber tenido cuando, más de un siglo después, fue visitado por Antonio de Ulloay Jorge Juan en 1735. Según los ilustres viajeros, ${ }^{13}$ el hospital semejaba "una pequeña ciudad, según el ámbito dilatado de su recinto...pues...luego que cada uno entra allí, donde ha de terminar el resto de sus días...forma una choza (que llaman bugío) para que le sirva de habitación, y vive en ella lo mismo que en su casa, sin que se le permita salir sino a pedir limosna, porque la asistencia y ración que les dan para vivir es escasa".

De acuerdo con un padrón efectuado por el Capitán don Juan del Real, de Infantería de las milicias disciplinadas de Cartagena, fechado el 7 de noviembre de $1777^{14} \mathrm{el}$ hospital constaba de 41 casas o bohíos, donde vivían, entre sanos y enfermos. 126 personas; en promedio, en cada bohío se alojaban tres personas.

\footnotetext{
11 Juan Bautista Montoya y Florez, Contribución al estudio de la lepra en Colombia, Medellín, Imprenta Editorial, 1910, p. 13.

12 Citado por Tomás Morales Muñoz, Mario Bernal Londoño y H. C. de Souza Araujo, "La lepra en Colombia". Encuestas epidemiológicas, en el capítulo titulado "Lazareto de Caño de Loro"', Bogotá, 1940, p. 6.

13 Eduardo Lemaitre, Historia General de Cartagena. Bogotá, Banco de la República, 1983, t. II, pp. 248-249. ${ }^{14}$ Archivo General de la Nación. (A.G.N.) Santafé de Bogotá, Lazaretos (Tomo único), ff. 920- 922 y
} 
Posteriormente, a raíz de la expedición de la Real Cédula del 30 de julio de 1784, se dispuso el traslado del hospital desde el sitio que ocupaba en Cartagena hasta un lugar extramuros de aquella plaza, en el sitio vulgarmente denominado La Cantera o Caño de Loro, según las reglas y medidas del plano formado por el ingeniero Don Antonio Arévalo, el mismo que había intervenido en la construcción de las murallas de Cartagena. De esa suerte, y de acuerdo con los planos mencionados, se ha debido emprender la construcción con materiales consistentes como piedra, argamasa, etc. Sin embargo, la misma cédula advierte que, por falta de recursos, provisionalmente, el material de construcción del hospital debía ser el mismo con que se habían levantado las viviendas de la estructura que se deseaba reemplazar, o sea paja y madera.

Aparentemente, esta situación subsistió durante toda la época colonial, ya que no conocemos documento donde se afirme que se hayan emprendido obras para seguir los planes de Arévalo, si bien en la relación de mando del virrey Mendinueta, de 1803, se dispuso "examinar el paraje conveniente y más proporcionado para fabricar el hospital general, de materiales más sólidos, como está resuelto por $\mathrm{S}$. M.; levantar el plano de la obra, calcular su gasto, proponer arbitrios para él". ${ }^{15}$ Por otra parte, en la documentación se advierte, especialmente a través de las muy escasas representaciones suscritas por los enfermos, ${ }^{16}$ que las condiciones de vida de estos siempre fueron penosas y que, en épocas de lluvia, las chozas sufrían frecuentes desperfectos y eventualmente se derrumbaban.

En cuanto a las condiciones de las construcciones que albergaban los leprosos, éstas no variaron de manera significativa desde el comienzo de la época colonial. Sin embargo, si se aceptan como ciertos los testimonios anotados, debe observarse una particularidad consistente en que gradualmente, el grupo leproso fue separado del universo de los sanos, como puede deducirse a través de las distintas etapas del desarrollo del hospital, así: en primer lugar, el hospital se construye cerca de la plaza de la ciudad. Luego, a raíz de quejas presentadas por los vecinos, es trasladado al sitio que ocupó hasta su traslado a Caño de Loro. Después, a instancias de San Pedro Claver, es rodeado por una cerca de tapia y, finalmente, es trasladado a

15 Ibid.

16 A.G.N. (Santafé de Bogotá), Lazaretos, ff. 824-825, 830, 967. 
Caño de Loro, en un punto cercano a Cartagena cuya única vía de acceso era la navegación marítima. De esa suerte, desde el principio de la erección del hospital, se gestó la política consistente en alejar, hasta donde fuera posible, los leprosos del resto de la población. En la adopción de este criterio, debieron haber ejercido una influencia determinante, tanto el temor de la población -generada por una representación arcaica, fuertemente arraigada-de tener contacto con los enfermos, así como también la idea, alimentada por la Corona, de que la enfermedad revestía carácter contagioso.

Por su parte, la real cédula de 1784 introdujo algunas innovaciones con respecto al tratamiento que había recibido la lepra hasta ese entonces. En primer lugar, se dispuso el traslado del hospital desde el sitio que ocupaba próximo al puerto de Cartagena hasta el sitio de Caño de Loro. A pesar de que en el artículo sobre Caño de Loro de Moralez Muñoz, Bernal Londoñc y De Souza Araújo, ${ }^{17}$ se menciona que el traslado se efectuó entre 1790 y 1795, ello debió ocurrir antes de la expedición de la real cédula de 21 de enero de $1791,{ }^{18}$ ya que en esta providencia no se menciona el hecho de no haberse cumplido con esta instrucción, como sí ocurre con lo relativo a b formación de las Constituciones del hospital, aspecto que en 1791 aún no había sido atendido y que comprendía, además, la determinación de la ración diaria a favor de los enfermos y la integración de un cuerpo científico integrado por "profesores de medicina, cirujía, botica y demás empleados".

Por otra parte, se menciona, en la real cédula de 1784 , que se crea un impuesto sobre el aguardiente, el cual servirá para el sostenimiento del hospital de San Lázaro, adonde deberán acudir todos los lazarinos del virreinato "Respecto de que todos los enfermos leprosos de él, debían llevarse al mencionado hospital de Cartagena". Estas modificaciones deben ser analizadas en relación con la situación que se presentaba hasta la expedición de la real cédula de 1784 .

\footnotetext{
17 Citado por Tomás Morales Muñoz, Mario Bernal Londoño y H. C. de Souza Araujo, "La lepra en Colombia Encuestas epidemiológicas, en el capítulo titulado "Lazareto de Caño de Loro", Bogotá, 1940, p.

18 A.G.N. (Santafé de Bogotá), Lazaretos, ff. 932-937.
} 


\section{PRIMERA EPOCA 1750-1784}

Es importante abordar lo relacionado con las modificaciones que afectaron la situación del hospital de San Lázaro a través de la disposiciones relativas al tratamiento de la lepra, de las cuales, las más significativas fueron la reales cédulas de 1784 y de 1791. De ese modo, se pueden establecer tres etapas, la primera de las cuales se extiende desde la mitad del siglo XVIII hasta la primera de las fechas mencionadas; una segunda época transcurre entre las dos providencias citadas y la tercera, va desde 1791 hasta finales de la Colonia.

Los primeros avances se efectuaron en cumplimiento de la real cédula del 21 de agosto de $1763 .{ }^{19}$ en la cual se dispuso en Cartagena la creación de una junta compuesta por el gobernador, los oficiales reales y el regidor más antiguo. Hasta 1780 sólo se habían efectuado dos juntas, una el nueve de marzo de 1768 y otra en abril de 1780 .

Una representación de don Francisco Alvarez de Castro había propuesto la formación de nuevas Constituciones, así como el traslado del hospital a otro sitio y la creación de nuevos arbitrios, iniciativas que fueron obstaculizadas en su momento a través de informes presentados por el cura del hospital, don Pedro $\mathrm{H}$. Juncal, y por el administrador del mismo, don Nicolás García. Acerca de la última junta, se convino avisar al gobernador "que hiciese prevenir alojamiento a los enfermos que se fueren remitiendo y que fuesen reconocidos por profesores". Por otra parte, se analizó el informe presentado por los ingenieros en el cual se proponían dos sitios para el traslado del hospital, uno en La Cantera y el otro en Buenavista. El ingeniero Antonio Arévalo se inclinó por el primero.

El 31 de octubre de 1781, se volvió a reunir la Junta y se acordó que el hospital debía erigirse con carácter provisional, en palma, a un costo calculado en 3000 pesos, en lugar de construirse de manipostería, caso en el cual los fondos invertidos se elevarían a la suma de 121.382 pesos, tres reales. En cuanto a los nuevos arbitrios, se estimó conveniente constituir un gravamen consistente en el cuartillo

19 A.G.N. (Santafé de Bogotá), Miscelánea 121, f. 469. 
de real por cada azumbre de aguardiente -lo cual, en otros términos, significaba que de cuarenta partes de aguardiente, una correspondía al impuesto destinado al Hospital- y en que se impusiera a cada carga de harina un gravamen de a ocho arrobas, dos reales, a la de cacao uno y medio reales y a la de azúcar un real.

La iniciativa del gravamen sobre el aguardiente se pasó a la consideración del Fiscal; a pesar de que el visitador general contradijo la imposición del cuartillo, finalmente, como se puede apreciar, las iniciativas aprobadas en la Junta celebrada en Cartagena constituyeron los antecedentes de la real cédula de 1784, en la cual se aprobaron casi en su totalidad -salvo los gravámenes establecidos sobre la harina, el cacao y el azúcar- las iniciativas propuestas en la junta.

En virtud de la real cédula de 1784 quedó definitivamente estatuido que todos los afectados de lepra del virreinato debían ser enviados al hospital de San Lázaro de Cartagena. De esa suerte, las autoridades adoptaban una medida de índole centralista. En otras palabras, la naturaleza marginal del grupo se subrayaba con la circunstancia de que sólo se admitía la existencia de leprosos en un solo punto del virreinato, y que este carácter ya no estaba determinado por factores dependientes de la voluntad de los enfermos. Estos ya no sólo eran marginales en su lugar de origen, en el seno de su propia familia, o en la localidad donde residían o de donde eran vecinos, sino que eran forzados a abandonar su sitio de vecindad y su círculo familiar y social, y obligados a concentrarse con sus iguales, en las condiciones en que le imponían las propias autoridades, separados para siempre del universo de los sanos. De esa suerte, al sentimiento de rechazo que padecían los leprosos entre la gente que los rodeaba, vinieron a agregarse ahora las consecuencias derivadas de las nuevas disposiciones oficiales, con sus naturales secuelas, produciéndose aquel estado en virtud del cual, la opinión que sobre los leprosos se formaba el público en general se veía reforzada por las políticas oficiales.

Esta situación la describe Sevilla Casas: "Hablando de manera general, los modelos oficiales y de la opinión pública se alimentan mutuamente dado que ellos representan el interés de la comunidad sana que se ve amenazada por el contagio. La opinión del común se formó a partir de una mezcla de terror y 
rechazo. El miedo visceral al contagio y la repulsión por la fealdad movía a la gente a expulsar a los elefancíacos. El paisaje físico y social de los pueblos y del campo se veía seriamente amenazado por los grupos rechazados". ${ }^{20}$

A pesar de que el Hospital estaba destinado a todos los leprosos del virreinato, no hemos encontrado una disposición que obligara a los funcionarios públicos a enviar los enfermos hacia ese centro asistencial antes de 1784, el cual, en realidad, parece que generalmente sólo sirvió para albergar a los provenientes de la Costa Atlántica y en especial de la ciudad de Cartagena. Por ejemplo, si reparamos en el censo ya mencionado anteriormente, realizado en $1777,{ }^{21}$ de los recluidos en el hospital no había un solo enfermo proveniente del interior del virreinato. Todos venían de la Costa Atlántica, especialmente de la ciudad de Cartagena. Si el hospital había sido fundado aproximadamente ciento setenta años antes para concentrar en él toda la población leprosa del virreinato, esa disposición no se había cumplido hasta el presente. Dentro de esa población encontramos nueve enfermos momposinos; de acuerdo con la documentación, periódicamente se efectuaban "sacas"de lazarinos con el propósito de enviarlos, desde esa población, la segunda en importancia de la provincia de Cartagena, hasta el hospital de San Lázaro. Así se observa en un memorial presentado el 27 de abril de $1800,{ }^{22}$ en el cual el cabildo de la villa solicita que de las rentas del hospital de San Lázaro de Cartagena se le envíen fondos ya que la renta de propios está exhausta. Se informa, además, que desde hace doce años no se efectúan remisiones ("sacas") de leprosos y que la villa está llena de ellos.

Sin embargo, la situación con respecto a la extensión de la lepra en algunas regiones del interior del virreinato, había sido, desde principios del siglo XVIII, alarmante, de tal modo que entre las medidas sugeridas para controlar la situación se solicitaba la construcción de más hospitales.

Se debe subrayar que las modificaciones introducidas en la política gubernamental acerca de lepra por la real cédula de 1784 fueron propuestas asumidas casi en su totalidad por la junta que en Cartagena estaba encargada

20 Elias Sevilla Casas, Los mutilados del oprobio. Estudios sobre la lepra en una región endémica de Colombia. Santafé de Bogotá. Colcultura, 1995, p. 62.

A.G.N. (Santafé de Bogotá). Lazaretos, ff. 921-922.

22 A.G.N. (Santafé de Bogotá), Lazaretos, ff. 56-59. 
de la administración del hospital. Es importante tener presente este origen porque es muy probable que las autoridades de las demás localidades del virreinato desde el principio no hubieran visto con buenos ojos que una porción del impuesto que gravaba el aguardiente se destinara al sostenimiento de una entidad que se hallaba fuera de sus respectivas jurisdicciones y sobre la cual ellas no tenían injerencia alguna. El 6 de septiembre de 1751, el cabildo de la villa de la Candelaria de Medellín, a instancias del procurador, dispuso "se pase a reconocer en los exidos de esta Villa la parte mas comoda para hospicio de los adolecidos. ${ }^{23}$ El 16 de septiembre de 1757 el cabildo dispuso avisar al gobernador acerca de la situación sobre la lepra, ya que "considerando sin fondo alguno el lugar para hacer Ospicio en qe alojar con separacion a los qe adolecen de semejante contagio, acuerdan el qe se conmueva el vecindario por medio de este Cvdo para qe concurran con sus limosnas a obra tan piadosa en qe todos son interesados. ${ }^{24}$

En ningún lugar era más apremiante la situación que en el Socorro y sus alrededores. En $1755,{ }^{25}$ el procurador general de la villa, Manuel Freiría, presentó un memorial al cabildo afirmando que, si al principio, la enfermedad había sido tolerada, en la fecha los leprosos ya sumaban veinte, y que, por lo tanto, se hacía indispensable tomar medidas para enfrentar el flagelo, tales como la construcción de un hospital. y la destinación de recursos para la atención de los enfermos, los cuales podrían provenir del cobro de un impuesto de medio real por cada arroba de carne de res, suma con la cual se atendería al sostenimiento de los enfermos, a cada uno de los cuales se le podía suministrar mensualmente "arroba y media de carne dos almudes de maíz media arroba de panela, cuatro libras de sal, ocho libras de zebo, una libra de jabón, medio millar de cacao y asimismo se le proverá de la azúcar y cosas medicinales que nesesitaren en sus urgencias". El cabildo aprobó la solicitud del procurador, pero las autoridades de Santafé no siguieron adelante con el examen de la iniciativa, hasta que no se procediera al reconocimiento de los enfermos, procedimiento sobre el cual no existe constancia de que se haya llevado a cabo. En ninguna parte se trae a colación la obligación de conducir los enfermos al hospital de San Lázaro de Cartagena.

\footnotetext{
${ }^{23}$ Manuel Monsalve "Acotaciones", Libro de acias del m. y. cavdo y rexmio de la villa de Medellín 1675-1815, Medellín, Imprenta Oficial. 1937, p. 163.

24 Manuel Monsalve, "Acotaciones", Libro de actas del m. y. Cavdo, p. 177.

25 A.G.N. (Santafé de Bogotá), Miscelánea 121, ff. 88-95.
} 
Veinte años después, en 1775, el cabildo del Socorro manifestó a la Real Audiencia "q hace cosa de treinta años apareció el primer leproso en esa villa, q debido a las casi nulas precauciones que se tomaron con la enfermedad se fue extendiendo mucho entre los ciudadanos, no solo de la villa sino de la provincia hasta tal punto $\mathrm{q}$ en esa fecha, había más de cien lazarinos deamvulando por las calles y campos con gran espanto de los moradores de estas regiones". ${ }^{26}$

Más tarde, también en 1775, los vecinos del Socorro presentaron un memorial solicitando nuevamente la erección de un hospital alegando, como motivos determinantes, la existencia de gente prominente entre los vecinos, la inconveniencia de separar a los enfermos de sus familias y los elevados costos que significaría para los leprosos carentes de recursos la realización del largo viaje hasta Cartagena, a pesar de los auxilios prometidos por el virrey sobre el particular, provenientes de la renta de alcabala. El párroco del Socorro, don Francisco de Vargas, ${ }^{27}$ también se sumó a ese clamor, solicitando que "se haga una Casa fuera de los caminos reales para evitar que no tengan tratos y contratos con ninguno y que de ese modo se puedan mantener retirados", y que "se les amoneste a las personas que están con el contagio que no traten ni tengan familiaridad con las demás gentes y que se les proiva que entren a la Iglesia y menos q los que mueran de semejante contagio se entierren en la iglesia".

Después de haberse efectuado los reconocimientos por parte de los doctores Juan Bautista Vargas y Juan José Cortés, visitó al Socorro el Fiscal Francisco Antonio Moreno y Escandón, sobre cuya participación con respecto a la política que se debía llevar a cabo en relación con la lepra, y en particular acerca de la conducción de los enfermos al Hospital de San Lázaro, es importante que hagamos un examen detenido. ${ }^{28}$

En primer lugar, es de destacar que Moreno y Escandón fue probablemente el mejor ejemplo en la Nueva Granada de despotismo ilustrado en un funcionario criollo, el cual, desde 1766, luego de su regreso de España, hasta 1780, ejerció

\footnotetext{
26 Horacio Rodríguez Plata. "Origen de la lepra en la antigua provincia del Socorro", Boletín de Historia y Antiguedades. Nos. 751-754, 1987, p. 751.

A.G.N. (Santafé de Bogotá). Lazaretos. ff. 76-86.

A.G.N. (Santafé de Bogotá), Lazaretos, ff. 92-94: 101: 109-110; 125.
} 
una influencia determinante en casi todos los asuntos de importancia de la administración colonial. Aparentemente, sólo José Celestino Mutis, "el oráculo de este reino", ${ }^{29}$ parece haber ejercido una influencia ininterrumpida más prolongada sobre los asuntos públicos atan alto nivel en el período colonial. ${ }^{30}$

En principio, para la construcción del leprocomio, Moreno insistió en que se destinara el dinero que la villa había dado dentro del rubro de los hospitales para llevar a feliz término ese cometido. Posteriormente, en junio de 1778, el Fiscal, en un informe al virrey, cambió de opinión: solicitó que los leprosos fueran enviados a Cartagena, insistiendo en el carácter contagioso de la dolencia al afirmar que "la lepra lazarina no dimana de algun alimento bebida o semejante principio por donde se contraiga en este territorio sino de una muger que vino con esta lepra", y requirió, además, la presencia de un facultativo para el reconocimiento de los enfermos.

Conocido el informe del médico Juan José Cortés, el Fiscal formuló comentarios encaminados a desvirtuar nuevamente la solicitud de erigir el hospital en el Socorro y tachó de exagerados los alcances que le dio el galeno a la enfermedad, criticando los métodos de curación propuestos. Ante una nueva solicitud, Moreno dispuso el envío de los enfermos al hospital de Cartagena El cabildo de San Gil, por su parte, despachó un grupo de trece lazarinos a la costa, para demostrar que las objeciones de las autoridades del Socorro, con respecto a la imposibilidad de la mencionada remisión, eran infundadas.

En el acervo documental relativo a esta actuación, es interesante destacar la que constituye indudablemente la pieza más curiosa. Sólo tres años antes de la Revolución de los Comuneros, el 13 de enero de 1778, el apoderado del cabildo del Socorro ante la Real Audiencia, Pablo Sarmiento, ${ }^{31}$ propuso para la adquisición del terreno donde se construiría el lazareto, que se decretaran

\footnotetext{
29 Polidoro Pinto Escobar y Santiago Díaz Piedrahita, José Celestino Mutis. 1732-1808, Bogotá. Universidad Nacional, 1983.

30 Para una biografía de Moreno y Escanden, leer el prólogo de Jorge Orlando Meló a la publicación del Fiscal que fue intitulada Indios y mestizos de la Nueva Granada afínales del siglo XVIll, Bogotá, Biblioteca del Banco Popular, 1985.

31 A.G.N. (Santafé de Bogotá), Lazaretos, f. 94.
} 
los siguientes recaudos: cuatro mil pesos de los bienes expropiados a los jesuítas, provenientes del Ramo de Temporalidades, además de los impuestos indirectos que se debían deducir de las transacciones sobre géneros de Castilla, la carne fresca y el aguardiente. Inmediatamente Moreno y Escandon, el 14 de enero, objetó que los recaudos no eran posibles por ser contrarios a la ley.

Y la solicitud es curiosa porque en el mismo lugar donde se fraguó la revuelta comunera, se proyectó el cobro de impuestos indirectos, que fue justamente la causa que posteriormente inspiró a los socorranos a levantarse. Evidentemente, para la comunidad no sólo importaba la imposición de nuevos tributos y la elevación de los existentes, sino la autoridad que los imponía. Se consideraba que los males no provenían ni del cabildo, ni del Rey, sino del "mal gobierno", representado por los déspotas ilustrados como el Fiscal del Crimen, cuyas opiniones con respecto a la construcción del lazareto y al tratamiento que debía darse a los lazarinos fueron aceptadas en todas las instancias por las autoridades de Santafé.

Por otra parte, es interesante subrayar el giro que tomaron las determinaciones del Fiscal con respecto a la construcción del hospital. Si en un principio se mostró conforme con la solicitud del Socorro, posteriormente cambió de opinión, y no cesó de insistir en la conveniencia de enviar los enfermos al lazareto de Cartagena. El vuelco mencionado sugiere que, luego de sopesar las razones en pro o en contra de la erección del hospital, con argumentos que muestran un adecuado conocimiento del tema, Moreno y Escandón cambió de parecer, tomando partido a favor del bando contrario a los intereses del Socorro. Y que, de contera, implicaban terciar en la vieja disputa local que esa villa tenía con la de San Gil, cuyo cabildo se apresuró a enviar una remesa de leprosos a Cartagena, con el objeto de demostrar que la construcción del leprocomio en el Socorro carecía de fundamento. En este episodio, uno más en la pugna entre las localidades de San Gil y Socorro, la primera pareció salirse con las suyas, si se tiene en cuenta, además, que los recaudos obtenidos en el Socorro por concepto de la contribución de hospitales, llamado comúnmente el noveno y medio, habían afluido hacia el hospital de San Gil, el cual atendía no solamente a la jurisdicción de esta localidad, sino a la de la villa del Socorro $^{32}$ y que se hallaba en pésimas condiciones, de creerse al doctor Gastelbondo en su visita

\footnotetext{
32 A.G.N. (Santafé de Bogotá), Lazaretos, f. 92.
} 
efectuada en 1779 ("allí se carecía de toda providencia"), ${ }^{33}$ pero al que por otra parte debía favorecerse evitando la fundación de otro hospital en el Socorro, según dictamen del visitador Gutiérrez de Piñeres. ${ }^{34}$

Como se observa, cualquier determinación que adoptara el Fiscal con respecto al tema en cuestión, implicaba tomar partido con respecto a una de las facciones en pugna, la de Socorro o la de San Gil. Tanto en este caso que, por su magnitud, puede parecer irrelevante, como con respecto a la aplicación de muchas de las reformas borbónicas, se tomaron determinaciones que, a raíz de medidas posteriores, pueden parecer erráticas y que demuestran que las autoridades españolas, empeñadas en crear un estado fuerte y centralizado, finalmente demostraron carecer de planes consistentes con respecto a muchos aspectos.

Con relación a la construcción de un hospital en el Socorro, en el siglo posterior cambiaron las perspectivas. Así, probablemente al tenor de la real cédula de 1791, que reformó la de 1784, fue construido, durante el año de 1800, el lazareto de El Regadillo, el cual, en razón de las quejas de los comerciantes, opuestos a su institucionalización por los riesgos que ofrecía al comercio, fue cerrado en 1820, en la era republicana, para conjurar la mala fama que la presencia de un lazareto había dado a la villa. ${ }^{35}$ Los leprosos, entonces, se refugiaron en un sitio localizado entre las parroquias de Guadalupe y el rancherío de La Contrata, llamado El Curo, cerca del camino real.

En 1821 el gobierno nacional comisionó a Ramón de la Peñuela para que procediera a construir en aquel lugar un poblado para los leprosos. El 14 de marzo de 1822, éste informó que ya se habían levantado 18 casas de "palo y paja" en una traza en cuadras alrededor de la plaza de la población, en cuyo marco se había erigido una capilla. Había surgido así el trazo de Contratación, como fruto de la política republicana de reorganización de los leprocomios. que también separó a los enfermos del trazo urbano. El 5 de abril de 1833 el

\footnotetext{
33 A.G.N. (Santafé de Bogotá), Lazaretos, f. 157.

${ }^{34}$ A.G.N. (Santafé de Bogotá), Lazaretos, f. 159.

${ }^{35}$ Los leprosos, entonces, se refugiaron en un sitio localizado entre las parroquias de Guadalupe y el Rancherío de la Contrata, llamado el Curo. Aída Martínez Carreño(ed-), Pueblos de Santander. Procesos de desarrollourbano, Bucaramanga, Universidad Industrial de Santander-Terpel, 1996.
} 
vicepresidente de la Nueva Granada, Francisco de Paula Santander, sancionó un decreto que establecía la existencia legal de tres lazaretos (llamados distritos de reclusión), en el territorio de la Nueva Granada: Contratación (Primer distrito), Caño de Loro (Segundo Distrito) y Agua de Dios (Tercer Distrito). El lazareto de Contratación se inauguró oficialmente el 15 de agosto de 1837 y el de Agua de Dios fue abierto hasta 1871. Contratación se entregó inicialmente al cuidado de la comunidad salesiana.

Así, todas las localidades del virreinato que contaban con leprosos, en el siglo XVIII se mostraron por completo reticentes a enviarlos al hospital de Cartagena. Solamente la villa de San Gil, que se disputaba con el Socorro la opción de crear un leprocomio en su territorio, y la cual, por lo tanto, se hallaba interesada en frustrar las aspiraciones de ésta, logró, venciendo todos los obstáculos que se presentaron, efectuar un envío de trece dolientes a Cartagena, al parecer el único que se efectuó en toda la Colonia desde el interior del virreinato. El hospital sólo sirvió para acoger lazarinos provenientes de localidades de la Costa Atlántica y de Panamá, a pesar de que esta última finalmente se sumó a la política adoptada por las demás localidades neogranadinas.

Hasta la real cédula de 1784, sin embargo, no se había dictado ninguna medida que obligara a centralizar en favor del hospital cartagenero recursos provenientes de todo el virreinato. Evidentemente, el carácter generalizado del gravamen sobre el aguardiente estimuló a las autoridades, y desde luego a los directivos del hospital, a exigir la remisión de los enfermos, medida que, a partir de la promulgación de la real cédula del 30 de julio del año mencionado, se hizo obligatoria.

Hasta entonces, el hospital había sido sostenido con arbitrios obtenidos en el puerto, gracias a privilegios concedidos por reales cédulas y a las gestiones del cabildo y a las autoridades del hospital. Un breve recuento de las determinaciones que al respecto se tomaron durante los siglos XVII y XVIII, anteriores a 1784, ilustra lo dicho. Entre las reales cédulas, podemos mencionar la expedida en Madrid el 21 de Febrero de 1641, uno de cuyos apartes dice así:

"Sea sustentado (el hospital) con las penas que en ella se aplican a mi camara y fisco por las Justicias, de que yo les tenía echa merced; y que por haver espirado, no tienen otro substentos, mas que el con su industria le busca dn. 
Joseph de las Alas, su mayoral, y este es muy limitado, por serlo las limosnas, y será imposible que con aquello se pueda sustentar el dho. Hospital, si yo no le buelvo a hazer merced de prorrogarle la sobre dha. por algunos años, ó hazerles otra mayor limosna, por que demas del sustento de los pobres, tiene el dho. Hospital necesidad de fábrica y de ropa. Y haviendose visto por los de mi consejo de las Yndias y consultandoseme, he tenido por bien de prorrogar á essa dha. ciudad, como por la presente le prorrogo la dha. merced que le tenía echa de las dhas penas de Camara, por quatro años más." ${ }^{36}$

Además, mediante real cédula expedida en Madrid, a 9 de agosto de 1651;" se había consagrado un impuesto sobre el derecho de anclaje a favor del hospital y se había formalizado la presencia de dos hacinadores,- o sea personas que recogían limosna en un platillo o bacinica. También, sobre unas casas ubicadas en la ciudad de Cartagena se empezaron a percibir rentas que beneficiaban al hospital, y sobre la cuales se extendió, asimismo, real cédula, expedida el trece de septiembre de mil setecientos setenta y cuatro.

Las rentas por concepto de arrendamientos se calculaban en 1784 en $1500 \mathrm{c}$ 1600 pesos anuales. Por ello, el administrador del hospital Rafael Antonio Tatis, en carta dirigida a las autoridades de Santafé, en febrero de $1780,{ }^{38}$ se quejaba de la cortedad de los ingresos, al afirmar que las rentas fijas solo llegaban a 1142 pesos cuando los gastos fijos, con los cuales se pagaban los salarios del capellán, los procuradores y sacristanes, eran de cuatro mil pesos cada año, aparte de que las rentas asignadas para el sostenimiento de los leprosos, que sumaban 112 en el momento, sólo permitían que a cada enfermo se le destinasen cinco octavos diarios. Sostenía, además, que el recaudo obtenido por concepto de los derechos sobre las mercancías que salían de la ciudad, en vista de la reducción en el tráfico marítimo, como consecuencia de la reciente guerra, habían sufrido un deterioro considerable. A lo anterior se sumaba la pretensión de los regidores de Cartagena de ocupar el espacio destinado a la Casa de Comedias ("...mediante a que el principal aposento se lo quieren apropiar los regidores de esta Ciudad").

\footnotetext{
36 José P. Urueta. (Comp.). Documentos para la historia de Cartagena. Cartagena. Tipografía de Antonio Araujo L., edición oficial a cargo de O'Byrne. 1888, t. 11, p. 1641.

37 Juan Bautista Montoya y Flórez, Contribución al estudio de la lepra en Colombia, Medellín, Imprenta Editorial, 1910, p. 12.

38 A.G.N. (Santafé de Bogotá), Lazaretos, ff. 169-170.
} 
En relación con la Casa de Comedias, es interesante precisar que, si bien la documentación existente sobre el particular es sucinta, se puede colegir que se obtenían algunas rentas para el sostenimiento del hospital, como resultado de los ingresos recaudados por concepto de los espectáculos teatrales ofrecidos en dicha Casa de Comedias ("...el Ramo de las Comedias puede ayudar en algo"). ${ }^{39}$

En resumen: a pesar de los esfuerzos tendientes para procurar unas rentas estables con destino al hospital, los ingresos estaban sometidos a fluctuaciones que no se compadecían con las necesidades de los enfermos ni con los gastos de la nómina. ${ }^{40}$

Por eso, la constitución de un impuesto que dependiera de las rentas estancadas del ramo del aguardiente pareció la oportunidad señalada para constituir unas rentas estables y para exigir de manera perentoria la afluencia al hospital de todos los leprosos del virreinato.

Detengámonos en la importancia que habían ido adquiriendo las rentas de aguardiente durante el siglo XVIII para las arcas reales. A pesar de que los planes para implantar el monopolio del aguardiente eran de vieja data, tan sólo en 1736 se reglamentó ese aspecto de las finanzas públicas y ya en 1738 ingresos apreciables de esta fuente empezaron a ingresar al fisco. Como lo observa Anthony Macfarlane: ${ }^{41}$ "El avance decisivo en el incremento de los ingresos del aguardiente sucedió después de la restauración del virreinato...Los resultados fueron sorprendentes. Los ingresos despegaron a principios de la década de 1740, al doblarse el promedio de recaudos entre 1741 y 1746 , y al cuadruplicarse durante los cincuentas y principios de los sesentas...Cuando fue introducido, el monopolio del aguardiente había fallado en medio de la oposición de los intereses económicos locales y de la inseguridad del gobierno; prosperó después del establecimiento del virreinato."

\footnotetext{
${ }^{39}$ Para Carlos José Reyes Posada, se trata del primer teatro que hubo en Colombia.

${ }^{40}$ A.G.N. (Santafé de Bogotá). Lazaretos, f. 169.

41 Anthony Mc Farlane. Colombia antes de la Independencia. Economía sociedad y política bajo el dominio Borbón, Santafé de Bogotá. Banco de la República - Ancora Editores, 1997, p. 303.
} 
Las rentas derivadas del aguardiante se convirtieron en un elemento fundamental del fisco virreinal. A pesar de que la porción correspondiente al hospital de San Lázaro sólo equivalía a una cuadragésima parte del valor del licor mencionado, de todas maneras el producto consolidado, luego que todas las administraciones enviaran lo correspondiente a un quinquenio, como lo estipulaba la real cédula, constituía una suma consistente y estable, en comparación con el producto de las rentas recibido hasta 1784, año en el cual las del quinquenio de aguardiente se calculaban en 11.151 pesos, siete reales veintinueve maravedíes anuales, a favor del hospital.

Mientras en la carta que hemos visto, el administrador Tatis se quejaba de que no excedían de los 1142 pesos, en 1780, en 1790 el total de rentas recaudado en las administraciones que lo habían reportado ascendía a la considerable suma de 19229 pesos, de los cuales tan sólo 36 pesos provenía de limosnas recogidas por un hacinador, de las contribuciones del jueves santo y de la venta de leña. ${ }^{42}$ En otras palabras: las rentas producidas por el aguardiente con destino al hospital de San Lázaro en Cartagena, a partir de la expedición de la real cédula de 1784 abrieron una nueva etapa para la administración de la lepra en el virreinato. Veremos que, como consecuencia de este incremento acelerado de los ingresos, a partir de ese momento aumentaría la presión ejercida por las distintas localidades en relación con la administración de los recursos derivados del monopolio del aguardiente y con el control ejercido sobre sus propios lazarinos.

\section{SEGUNDA ETAPA 1784-1791}

Si se repasa la real cédula de 1784, la misma que estableció el cuartillo de aguardiente y la orden de enviar todos los lazarinos del virreinato a Cartagena, observamos que a las autoridades encargadas del manejo del hospital se les exigieron ciertas condiciones, tales como el traslado del hospital al sitio de Caño de Loro, la creación de una nómina en la cual se incluían individuos con formación científica o seudocientífica, como médicos o sangradores y la formación de estatutos.

\footnotetext{
42 A.G.N. (Santafé de Bogotá), Miscelánea 121, ff. 39-76.
} 
Con relación al recaudo del impuesto sobre el aguardiente, una de las reformas introducidas por los virreyes en cuanto a la administración de la hacienda pública, consistió en que se intentó abolir el procedimiento mediante el cual las rentas se remataban, de suerte que en ocasiones, gran parte del producto de las mismas quedaba en poder del asentista, reemplazándolo por el recaudo directo de las mismas. Ello, desde luego, repercutió en un aumento sustancial del recaudo. A pesar de que éste siempre fue irregular, ya que a veces no se enviaban a tiempo a Cartagena las sumas recaudadas, o los recaudos fueron parciales, de todas maneras, los ingresos, como vimos, aumentaron sustancialmente. Por otra parte, en auto de 11 de marzo de 1788, se dispuso que "al Hospital debe corresponder el sobrante que queda por la minoracion de medida en el aguardiente de España." ${ }^{43}$

Estas sumas se destinaron en principio a la traslación del hospital, medida que solamente se empezó a cumplir el primero de diciembre de 1786, habiéndose verificado antes del 13 de marzo de $1789,{ }^{44}$ tal como quedó registrado en la junta respectiva, en la cual también se aprobaron las Constituciones presentadas por el administrador. Sin embargo, con respecto a este último punto, al parecer a las Constituciones no se les había dado un trámite acabado por cuanto en la real cédula de 1791, se afirmaba que aún no habían sido presentadas. Por otra parte, nuevas Constituciones se presentaron el 19 de febrero de 1810, y en diciembre de 1817.

En cuanto a la elección de médicos, sabemos que mediante auto del 30 de septiembre de 1786, se nombró como médico del hospital el doctor Andrés González Estrella, con un sueldo de carácter provisional de dieciséis pesos mensuales de salario, "con calidad de por ahora y mientras se arreglaba el hospital con los precisos asistentes, y se señalaba al médico el salario correspondiente. ${ }^{45}$ Posteriormente, a la muerte de este galeno, fue nombrado en su reemplazo Manuel Julián de Gastelbondo, "con la asignación que este tenía."

43 A.G.N. (Santafé de Bogotá). Miscelánea 121, f. 470.

${ }^{44}$ A.G.N. (Santafé de Bogotá). Miscelánea 121, f. 470.

${ }^{45}$ A.G.N. (Santafé de Bogotá), Miscelánea 121, f. 466 r.

${ }^{46}$ A.G.N. (Santafé de Bogotá), Miscelánea 121, f. 466 r. 
Podemos mencionar un ejemplo bastante revelador acerca de la actitud de las distintas localidades del virreinato con respecto a la remisión de sus respectivos enfermos al hospital de Caño de Loro. La provincia que, aparte de las de Cartagena y Santa Marta, en la Costa Caribe, se encontraba más próxima a Cartagena, era Panamá. ${ }^{47}$ Desde allí, antes de la reforma de 1784 . al parecer ya había sido enviado un pequeño remanente de enfermos. Sin embargo, cuando, en virtud de auto del 31 de agosto de $1785^{48}$ se instó al gobernador de Panamá a cumplir la real cédula, empezaron una serie de dificultades que evitaron finalmente que la orden de remisión fuera llevada a cabo. En primer lugar, el administrador de aguardientes argumentó que hasta el momento no se había recaudado cantidad alguna "perteneciente al Ramo de los lazarinos y no haber orden alguna para suplir o adelantar a cuenta de lo que después se supliese". A pesar de que esa dificultad fue subsanada, ya que se dispuso el reintegro respectivo, seis meses después otro funcionario, el Procurador General, expuso otros argumentos que dificultaban el cumplimiento de la orden. En su lugar, propuso que se reconociese un auxilio de dos pesos para cada uno de los diez leprosos que vivían en una casa en las afueras de la ciudad y que hasta el presente habían sobrevivido de las limosnas que recibían de la población, con grave riesgo de contagio por parte de ésta. Se proyectó, en consecuencia, decretar un gravamen de dos reales semanales que debían pagar cada una de las pulperías (tiendas) de la ciudad. A pesar de que la medida fue aprobada con dictamen del asesor del cabildo, finalmente no se le dio curso por cuanto se consideró que el gobernador carecía de facultades para ello.

No obstante, las autoridades panameñas siguieron insistiendo en la dificultad de remitir los enfermos "que se reducen a que los conductores en ese caso serían contaminados." 49 El parecer fue refrendado con el dictamen de tres médicos y concluyó con la solicitud de "que lo que produjere el ramo destinado en Panamá se aplique a los enfermos para su sustento en su misma patria."

47 Sobre Panamá ver especialmente A.G.N. (Santafé de Bogotá), Lazaretos, ff. 585-600; 610-628; 732-761; 780-804.

48 A.G.N. (Santafé de Bogotá), Miscelánea 121, f. 466 r. - v.

49 A.G.N. (Santafé de Bogotá), Miscelánea 121, f. 467. 
Protestó el administrador de Cartagena y se procedió al reconocimiento de los leprosos existentes en la provincia de Panamá, ocurriendo que ocho "resultaron enteramente rematados y casi inmóviles y tres menos deplorables", a lo cual se añadía que la falta de fondos hacía difícil la manutención y el transporte de los enfermos, así como la reparación de la casa donde vivían. En auto del 6 de diciembre de 1787, en vista de la extrema postración de los enfermos, se dispuso que para separarlos de la comunicación con los sanos, se destinasen treinta pesos mensuales para la manutención de cada uno, que provendrían de la renta de aguardientes, cifra que disminuiría a medida que fuesen muriendo. Posteriormente, se siguió insistiendo en la necesidad de remitir los enfermos a Cartagena, tan pronto como los médicos hubieren diagnosticado la aparición de la enfermedad, para evitar una situación como la que todavía se vivía en marzo de 1791, cuando aún subsistían seis enfermos en la provincia de Panamá que debían ser sostenidos con veinte pesos mensuales. Los gobernadores de Panamá y de Portobelo representaron acerca de la dificultad en el transporte, pero en una orden del virrey Ezpeleta, del 9 de enero de 1793, se insistía todavía en organizar un viaje "a través de contrata particular con los traficantes". De esa suerte, a pesar de la relativa proximidad de Panamá a Cartagena, mientras se prolongó la vigencia de la Real Cédula de 1784 no se había aún efectuado un solo despacho de leprosos hacia el hospital de Caño de Loro.

Igual situación ocurría en otro sector del virreinato, en la Real Audiencia de Quito, ${ }^{50}$ situada a considerable distancia de Cartagena. ${ }^{51}$ En virtud de auto proveído el 11 de septiembre de 1785, se comunicó al presidente de Quito la real cédula del año anterior, preguntándole si en su opinión era posible el traslado de los enfermos a Cartagena, o si era preferible el "establecimiento de algún Hospital en aquella provincia". Contestó el Presidente que era imposible el traslado de las tres o seis personas leprosas que había en la provincia y que, en su defecto, había dispuesto "se recogiesen con la debida separación y cautela en la casa que para Hospital de virolentos se había mandado construir por el Superior Gobierno." Concluía su informe proponiendo que lo recaudado del cuartillo de aguardiente se destínase al sostenimiento de la casa mencionada. Contradijo la opinión del Presidente de Quito el Administrador del Hospital de Cartagena,

\footnotetext{
50 Sobre Quito Ver especialmente A.G.N. (Santafé de Bogotá), Lazaretos, ff. 358-361; 937-939; 944-946; 953; 999-1002; 1006-1008.

51 A.G.N. (Santafé de Bogotá), Miscelánea 121, f. 468.
} 
argumentando que el transporte por agua haría viable e incluso fácil el traslado de los enfermos hasta el puerto caribeño. Por su parte, el presidente de Quito, con la aprobación del fiscal, dispuso que los seis enfermos se sostendrían en esa ciudad con el producto del cuartillo de aguardiente. Por lo pronto, en auto del 25 de junio de 1787, se previno consultar al Superior Gobierno acerca de si se debía insistir en la traslación de los enfermos hasta Cartagena, o si, por el contrario, era preferible proceder a la construcción de un hospital. Comoquiera que el gobierno de Cuenca ${ }^{52}$ expresara asimismo la voluntad de construir un hospital en esa población, se "mandó esperar la resolución de su majestad en decreto del 1 de junio de 1788".

De ese modo, no bien fue puesta en funcionamiento la real cédula de 1784 . las distintas localidades del virreinato, cada una por sí, adoptó una postura tendiente a evitar que el recaudo por concepto del cuartillo de aguardiente con destino al hospital de Cartagena fuera remitido, y que más bien fuese destinado a la construcción y sostenimiento de hospitales en cada una de las localidades donde hubiera leprosos. Desde luego, el mejor argumento para evitar la remisión de los fondos consistía en obstaculizar hasta donde fuera posible, el envio de los enfermos locales. En este caso, un factor de naturaleza económico fiscal -los relativamente cuantiosos recaudos por concepto del cuartillo de aguardiente- fue el que determinó la dirección que finalmente adoptó la política de la Corona con respecto a los lazarinos. Sin embargo, como se había demostrado con la remisión de un contingente de leprosos desde San Gil, localidad relativamente apartada de Cartagena, si bien el transporte de los enfermos era difícil, y los encargados de realizarlo veían con horror la posibilidad de contagiarse, se presentaba de todas maneras posible.

Por otra parte, el contenido de la documentación no permite precisar hasta qué punto pesaron más los argumentos de tipo humanitario que cada localidad esgrimía para defender, como prioridad, a sus propios leprosos, o si, en realidad, se trataba más bien de evitar que los fondos derivados del cuartillo de aguardiente fueran enviados a Cartagena en lugar de ser invertidos en la propia localidad o provincia donde se recaudaban.

52 A.G.N. (Santafé de Bogotá), lazaretos, f. 362. 
Si se ahonda en el análisis, no se puede desconocer, en resumen, que el problema de la lepra y de los recursos destinados por la Corona a solucionarlo sirvió para resaltar las diferencias que existían entre las localidades del virreinato de la Nueva Granada. Esas rivalidades, en cada caso particular, asumían una dinámica diferente, y se planteaban a veces entre Cartagena y las diferentes localidades y provincias, o inclusive entre localidades que preferían reconocer ventajas a favor de Cartagena antes de negociar sus propias diferencias.

Tal evento ocurrió, como ya se anotó, con los resquemores existentes entre centros urbanos tan cercanos como San Gil y Socorro. Las autoridades sangileñas, empeñadas en obstaculizar por todos los medios posibles la construcción de un leprocomio en el Socorro, - lo cual hubiera supuesto que tributos recaudados en San Gil se hubieran empleado en el Socorro, como en el caso del gravamen del noveno y medio destinado a los hospitales- hicieron todo cuanto estuvo a su alcance para transportar a "sus" leprosos hasta Cartagena, y finalmente lo lograron. Por qué no lo hicieron así las autoridades del Socorro, las de Panamá y las de Quito?.

A pesar de que la documentación no lo expresa de manera explícita, y de que el argumento que se opone al cumplimiento de la real cédula es invariable -la dificultad del transporte- consideramos que cada caso merece un análisis particular. El argumento, por ejemplo, en el caso de Quito, se debe admitir dada la enorme distancia que lo separaba de Cartagena. Es preciso destacar la importancia del aislamiento en la geografía neogranadina: "Como es de esperarse, el aislamiento era la nota predominante en el desenvolvimiento de este reguero de pequeñísimas poblaciones españolas, separadas por enormes distancias, por barreras orográficas y selváticas y por zonas dominadas por indígenas hostiles." 53

Pero no se puede argumentar lo mismo en el caso de Panamá, por su cercanía a Cartagena; en cuanto al Socorro, ya sabemos que las dificultades que hubiera implicado el traslado de sus leprosos hasta el puerto caribe eran las mismas que encontraron los de San Gil, y que estos habían podido superar.

${ }^{53}$ Luis Jaramillo y Luis M. Cuervo, La configuración del espacio regional en Colombia, Bogotá, Cede, Universidad de los Andes, 1987, p. 295. 


\section{TERCERA ETAPA 1791-1810}

El argumento de la imposibilidad del transporte terminó por imponerse. El Superior Gobierno, que en principio, a través de la Real Cédula de 1784, había aceptado casi en su totalidad las iniciativas propuestas por la junta administradora del hospital de Cartagena, acabó plegándose a las demandas de las demás localidades. Es importante detenernos, por lo menos, en formular algunas hipótesis al respecto.

Es innegable que, como ocurrió con muchas de las reformas borbónicas que se implantaron o se quisieron implantar en la Nueva Granada, si en principio se intentaron aplicar sin hacer la más mínima concesión a los intereses locales, muy pronto debieron atenderse este estilo de solicitudes, y el espíritu centralizador y autoritario que inspiró la aplicación de las reformas acabó debilitándose. Sobre este particular, inclusive se pueden establecer distintas etapas, no sólo a nivel local o del virreinato de la Nueva Granada, sino de la propia metrópoli. Es bien claro que las reformas borbónicas y los cambios institucionales específicos que surgieron bajo su influencia, como los relativos a la lepra, no se implantaron tan pronto como los miembros de esa dinastía empezaron a ocupar el trono, a partir de 1700, sino que el impulso reformista tanto en España como, desde luego, en las colonias, sólo adquirió una dimensión apreciable a partir de la ascensión al trono de Carlos III (1759). Por otra parte, al término del reinado de este monarca, el citado impulso decreció, y su sucesor, Carlos IV, (1788) hubo de efectuar algunas concesiones a aquellos sectores inconformes con el centralismo excesivo del Estado. El apogeo en la aplicación de las reformas borbónicas no alcanzó a durar más de un tercio de siglo en la metropoli.

En cuanto a la aplicación de las mismas en las colonias americanas, su duración es aún menor. Comenzó con la aplicación de reformas militares en Cuba en $1763-1764,{ }^{54}$ las cuales inspiraron las que se intentaron poner en marcha en la Nueva Granada, con resultados contradictorios - en especial por la oposición de las élites locales del interior del virreinato-. Como hemos visto anteriormente, la suerte del resto de las reformas fue contradictoria.

\footnotetext{
${ }^{54}$ Ver Alian J. Kuethe, "The early reforms of Charles III in New Granada", 45o. Congreso Internacional de Americanistas, Bogotá, Ediciones Uniandes, 1988, pp. 69-80.
} 
Lo propio puede predicarse en el caso de la política con respecto a la lepra, al menos si se la considera desde el punto de vista de la adopción de una postura centralista más o menos rígida que hacía del hospital una entidad hacia la cual debían afluir todos los recursos en la medida en que era la institución llamada a atender todos los leprosos del virreinato.

Por otra parte, como se colige a través de lo que hemos visto, no se puede desconocer que las modificaciones que experimentó la situación creada alrededor del hospital de San Lázaro se articularon, en mayor o menor medida, con los cambios que experimentaron las reformas borbónicas en la Nueva Granada. Es evidente que se puede ilustrar como ejemplo de esas modificaciones la transformación experimentada entre la real cédula de 21 de agosto de 1763 que dispuso la creación de una Junta encargada de la administración del hospital, la cual señaló una serie de iniciativas que posteriormente se cristalizaron mediante las reales cédulas de 1784 y de 1791. En ese período se puede señalar, como ingrediente adicional, el reforzamiento del centralismo a través de intervenciones enérgicas como la de Moreno y Escandón, quien, si en principio apoyó la construcción de un leprocomio en el Socorro, posteriormente se opuso tenazmente a esta iniciativa, consolidando, de esa suerte, la posición del Hospital de San Lázaro. A pesar de que la Revolución de los Comuneros impidió que las reformas borbónicas se aplicaran con la energía como el visitador Gutiérrez de Piñeres había proyectado que se ejecutaran, es probable que la intervención decisiva del Socorro en el mencionado levantamiento -de todas maneras la iniciativa de abrir un hospital sólo se vino a revivir después de la cédula de 1791- hubiera favorecido los intereses cartageneros los cuales, de todas maneras, recibieron el máximo espaldarazo con la adopción de la real cédula de 1784 .

Sin embargo, como hemos visto, si bien desde Cartagena se procuró dar cumplimiento a las condiciones estipuladas en la real cédula de 1784, desde el principio las localidades se negaron a despachar a sus enfermos a San Lázaro y pretendieron erigir hospitales en cada una de ellas, posición que encontró rápida acogida entre las autoridades centrales. Llama la atención que, mientras una localidad pujante como el Socorro, sólo encontró eco para construir un hospital propio en la fase final, a través de la fundación de uno al cual 
sólo se opusieron los comerciantes de la localidad, ${ }^{55}$ no obstante contar con el núcleo de lazarinos más numeroso del virreinato, con excepción del de la actual costa caribe colombiana, la Corona acogió con facilidad las pretensiones de otras ciudades cuyas poblaciones enfermas eran sumamente reducidas en comparación con el núcleo del Socorro. Así. mientras en Panamá los leprosos no superaban los diez y en Quito la población no subía de veinte, en el Socorro y sus alrededores la población no bajaba de sesenta.

Si bien las motivos aducidos para la creación del plan general de hospitales en todo el virreinato se fundamenta básicamente en la distancia considerable entre Quito y Cartagena, aspecto que parece incuestionable, sin embargo no se puede desconocer que este solo motivo sirvió para proponer la erección de hospitales en otros centros urbanos menos distantes de Cartagena que Quito. Las ventajas que inicialmente sólo hubieran debido otorgarse a ésta, se extendieron a otras localidades, de suerte que se estableció un sistema de descentralización en el manejo de los leprocomios en laNueva Granada, y sólo se conservó la posibilidad de que convergieran hacia el hospital cartagenero aquellos fondos provistos por localidades donde aún no se habían construido centros hospitalarios.

A pesar, insistimos, de que la descentralización administrativa benefició a las localidades del virreinato en la medida en que todas quedaron igualmente facultadas para abrir leprocomios, es interesante advertir que esa política se originó en principio gracias a la negativa a la remisión de los leprosos de las ciudades que constituían o habían constituido cabeceras de Audiencias distintas de las de Santafe, precisamente Quito y Panamá. ${ }^{56}$ Cada una de ellas era o había sido el centro de una circunscripción administrativa, judicial y militar que, si bien no era autónoma frente al virrey, sí lo era frente a la Audiencia de Santafé. Por ello, el parecer del virrey Ezpeleta en su relación de mando era que "no conviene se erija en el Distrito de esta Real Audiencia otro hospital que el establecido en Cartagena." ${ }^{57}$

\footnotetext{
55 Aída Martínez Carreño (ed.). Pueblos de Santander. Procesos de desarrollo urbano. Bucaramanga, Universidad Industrial de Santander-Terpel, 1996.

56 La Audiencia de Panamá había sido disuelta en 1751. Ver Hans-Joachim Konig, En el camino hacia la nación, Santafé de Bogotá, Colección Bibliográfica Banco de la República, 1994, p. 63.

57 Elias Sevilla Casas, Los mutilados.... Santafé de Bogotá, Colcultura, 1995.
} 
Esta consideración es pertinente ya que, por otra parte, si, valga el ejemplo, se examina el origen de la documentación que se ha tenido en cuenta para esta investigación, se observa que sobre el problema de la lepra no se ha allegado información acerca de la actual república de Venezuela. Esto obedece a que la Capitanía General que ocupaba ese país, no obstante pertenecer formalmente al virreinato, por sí misma constituía una unidad administrativa que merecía un tratamiento especial de parte de la Corona, con mayor autonomía que la que se le reconocía incluso a las Audiencias. Prueba de lo anterior es que en las Relaciones de Mando de los Virreyes, se observa que no se hace una alusión detallada a la situación interna de la Capitanía, como sí ocurre con el resto del virreinato.

También en el interior de las Audiencias las diferencias regionales se siguieron manifestando en relación con la creación de hospitales. En el caso de la Audiencia de Quito, la propia capital nunca pudo aspirar a reproducir la situación de Cartagena con respecto a construir un hospital único para toda su jurisdicción, sino que rápidamente los centros urbanos más importantes, $\mathrm{y}$ por lo tanto en cierto sentido rivales de la ciudad, aspiraron a construir hospitales que no sólo sirvieran a los intereses de la localidad propiamente dicha, sino a los de su zona de influencia. Ello ocurrió no sólo con Guayaquil, ${ }^{58}$ la tradicional rival de Quito, sino también con Cuenca y Popayán. Por otra parte, en el caso de que el establecimiento de salud respectivo no gozara de la aprobación de las autoridades locales, Cartagena siguió siendo el centro elegido donde se debían enviar los enfermos. Así ocurrió, por ejemplo, con algunos casos de lepra presentados en Buga, en 1793, ciudad que se hallaba dentro de la jurisdicción de la Audiencia de Quito. ${ }^{59}$ A pesar de que no consta que los enfermos hayan sido remitidos a Cartagena, sí se comenzaron a realizar gestiones para llevarlos a esa ciudad. En todo caso, no se menciona que se hubiera intentado dirigirlos a Quito, ni tampoco parece que hubiera dado resultado una operación propuesta por Joaquín Fernández de Soto, ${ }^{60}$ a nombre de su padre Fernando, relativa a la negociación de un lote en inmediaciones de la población, para la construcción de un lazareto. A pesar de haber sido comprado el citado lote con contribuciones de todo el vecindario, y que por

58 A.G.N. (Santafé de Bogotá), Lazaretos, ff. 949; 987 y 1004.

A.G.N. (Santafé de Bogotá), Lazaretos, ff. 44-52.

A.G.N. (Santafé de Bogotá). Miscelánea 121, f. 468v. 
lo tanto este terreno debía quedar a nombre de las rentas de propios, se desistió de la construcción del hospital por falta de fondos. Tampoco en la documentación respectiva se menciona un hospital que se proyectaba construir entre Cali y Popayán para servir esa zona. En resumen: todavía después de la real cédula de 1791 se sostenía que no se debía construir "en el Reino otro hospital de lazarinos que el de Cartagena, al que se remitiesen todos los enfermos a costa del cuartillo sobre el aguardiente, salvo que los dichos tengan caudal propio con que costearse", 61 aspecto que no se contemplaba en la providencia de 1791, en la cual sólo se prescribía que los sobrantes que quedaran luego de la construcción de los respectivos hospitales y de su sostenimiento se deberían remitir a Cartagena.

Contrasta esta actitud de las autoridades de las distintas localidades del virreinato con el comportamiento observado en Santafé, la capital del virreinato, con respecto a los problemas derivados del tratamiento de la lepra. Mientras que para los demás cabildos el principal problema era, sin duda, el de atender a sus propios leprosos con los recursos generados en su propia jurisdicción por concepto del cuartillo de aguardiente, para el cabildo de Santafé la remisión a Cartagena de los leprosos encontrados en la ciudad y sus alrededores no constituía un asunto de señalada importancia. En la documentación relativa a la lepra en la ciudad, la preocupación se concentraba en los controles que se debían adoptar con el objeto de contener la expansión de la enfermedad, y en proceder al reconocimiento de los enfermos por médicos tales como José Celestino Mutis, el padre Isla, Honorato de Vila, Sebastián López Ruiz, etc.con base en los informes suministrados por los alcaldes de barrio. ${ }^{62}$ Es más: cuando se sugirió la necesidad de construir un leprocomio, la iniciativa se refirió más bien a la conveniencia de establecer un centro donde pudieran concentrarse los leprosos que fueran hallados en la ciudad, antes de enviarlos al hospital de San Lázaro en Cartagena, destino final que a los ojos de las autoridades de la ciudad parecía indiscutible. Por otro lado, la necesidad de construcción de un lazareto se refería más bien al deseo de evitar las molestias derivadas de la atención de los lazarinos en el hospital de San Juan de Dios de la ciudad, con lo cual se exponía al resto de la población afectada de otras enfermedades al contagio de la lepra.

61 A.G.N. (Santafé de Bogotá), Miscelánea 121, f. 469.

62 A.G.N. (Santafé de Bogotá), Lazaretos, ff. 18-21; 900-908. 
¿Qué explicación puede darse sobre la actitud de las autoridades de Santafé, que aparentemente no se hallaban dispuestas a disputarle al hospital de San Lázaro de Cartagena la calidad de primera institución para la atención de la lepra en el virreinato? La documentación no ofrece ninguna indicación al respecto, pero se podría mencionar el hecho de que posiblemente las autoridades santafereñas estaban interesadas en eludir un enfrentamiento con la Real Audiencia y con el virrey o entre aquélla y éste, ${ }^{63}$ en punto a los asuntos de política sanitaria, y también en evitar revivir la polémica que en torno a decidir cuál sería la capital del Virreinato, en su momento se había originado entre Santafé y Cartagena. ${ }^{64}$

Se puede aseverar que el plan de descentralización fue un reconocimiento a las pretensiones locales que se expresaban a través de los cabildos. Al parecer, con estas concesiones, de alguna manera, se reconocía que, por lo menos en el caso de la Nueva Granada, el afán de diseñar un modelo centralista para la atención de la lepra había sido dejado de lado, y que era preferible, con tal de preservar la autoridad real, efectuar concesiones de tipo administrativo y fiscal a los cabildos, compartiendo, de esa suerte, los beneficios obtenidos por las reformas fiscales en especial en cuanto a la administración de las rentas estancadas de los aguardientes. Así, por paradójico que parezca, las ventajas obtenidas a través de una reforma que mejoró efectivamente los recaudos en beneficio de las Reales Cajas, afluyeron nuevamente a las administraciones locales.

La coyuntura creada en virtud de la puesta en marcha del plan general de hospitales deterioró la situación financiera del hospital de Cartagena. A pesar de que la real cédula de 1791 era clara en el sentido de que, si no se construían hospitales en las diversas localidades, los fondos recaudados en éstas derivadas

63 Ver Jaime Jaramillo Uribe. "La administración colonial", Nueva Historia de Colombia, Bogotá, Editorial Planeta, t. V, p. 181. Allí se nos recuerda que "las colisiones entre virreyes y Real Audiencia, sobre todo, fueron continuas".

${ }^{64}$ Ver Germán Colmenares, "Factores de la vida política colonial", Nueva Historia de Colombia, Bogotá, Planeta Editorial Colombiana. 1989. t. V. p. 201. Sobre cual de las dos ciudades, Cartagena o Santafé, debía ser capital del virreinato se adelantaron entre 1720 y 1723, varias consultas entre las autoridades eclesiásticas y civiles de las principales ciudades del territorio que habría de comprender el virreinato, resultando que las opiniones estaban divididas de manera casi simétrica a favor de una u otra opción. 
del cuartillo de aguardiente debían afluir a la casa de salud de Caño de Loro, se presentaron eventos en que ni se construyeron nuevos hospitales, ni las sumas recaudadas se enviaron con destino al hospital mencionado. Un caso como el descrito se presentó en Popayán, localidad donde hasta 1803 las diligencias encaminadas a la construcción de un nuevo hospital no habían dado resultado, sin que por otra parte, se hubieran remitido a Cartagena las sumas recibidas por concepto del impuesto a favor de los lazarinos. Por ello, en ese año, el administrador de Caño de Loro, Rafael Antonio Tatis, elevó una representación solicitando el envío de fondos desde Popayán, basado en la orden del 25 de septiembre de 1786 que disponía el envío "cada tres meses, del cuartillo de real sobre el azumbre de aguardiente vendido". ${ }^{65}$

De alguna manera, esta situación que privilegiaba los intereses locales se asemejaba a la presentada a principios del siglo XVII, cuando aún no habían sido implantadas las medidas de carácter institucional que modificaron el tratamiento de la lepra.

Queda por inquirir acerca de los cambios que en la condición de la marginalidad introdujeron las nuevas disposiciones. La Corona siempre mantuvo la creencia de que la lepra era contagiosa y que, por lo tanto, el único camino que había que tomar con relación a los enfermos era aislarlos del mundo de los sanos, empleando todas las medidas que estuviesen en posibilidad de ser aplicadas para lograr tal cometido. Por ello el hospital fue trasladado al principio fuera de la ciudad, posteriormente cercado y finalmente trasladado a Caño de Loro. Sin embargo, cuando se abrió la posibilidad de que se construyeran hospitales, la condición de marginalidad de los enfermos cambió un tanto, en razón de que el enfermo quedaba aislado en un territorio que no le era ajeno y subsistía la posibilidad de tener algún contacto con sus familiares y conocidos. Justamente, en el caso del hospital de San Lázaro en Cartagena, las protestas en contra de su erección en Caño de Loro provinieron de los enfermos que veían así reducida la posibilidad de ver a sus familiares y demás relacionados.

65 A.G.N. (Santafé de Bogotá), Lazaretos, ff. 33-43. 


\section{CONCLUSIONES}

Las disposiciones que se promulgaron durante la segunda mitad del siglo XVIII articularon las reformas relativas a la lepra, -aspecto de la salud pública que, al lado de la viruela, fue el que más atención generó de parte de las autoridades virreinales- las cuales no produjeron los resultados esperados por la Corona.

El carácter contagioso que se le otorgaba a dicha enfermedad permitió que los aquejados con ella recibieran un tratamiento aún más discriminatorio que el otorgado en épocas anteriores, al disponer la construcción de la nueva sede del hospital de San Lázaro, en un punto distante de la ciudad de Cartagena, accesible por vía marítima, y donde debían ser concentrados todos los enfermos del virreinato de la Nueva Granada.

Si hasta 1784 , los recursos con que contaba el hospital para el sostenimiento de los enfermos, resultaban a todas luces insuficientes, a partir de esa fecha, con la creación del impuesto que gravaba el consumo de aguardiente, la situación del hospital mejoró ostensiblemente.

A pesar de ese incremento en los ingresos, las protestas presentadas por localidades del virreinato distintas de Cartagena, desdibujaron la estructura como había sido concebida la reforma, y culminaron en la real cédula de 1791, en virtud de la cual se promulgó un plan general de hospitales que permitía la construcción de centros de salud en las localidades con base en los tributos recaudados sobre el tributo de aguardiente, los mismos que originalmente sólo estaban destinados al hospital de San Lázaro en Cartagena.

Como consecuencia de lo anterior, si bien sólo se intentaron construir algunos hospitales, de todas maneras el propósito inicial, de carácter centralista, que había inspirado la reforma, se desvirtuó, y más bien se dio paso a las aspiraciones de carácter localista de los distintos centros urbanos neogranadinos. La Corona debió resignarse a adoptar una actitud que conciliara la línea de conducta autoritaria propia del despotismo ilustrado con las aspiraciones de las localidades. 


\section{BIBLIOGRAFIA}

\section{FUENTES DOCUMENTALES}

Archivo General de la Nación (Santafé de Bogotá), Sección Colonia, fondos:

Lazaretos (Tomo único)

Miscelánea 121

\section{BIBLIOGRAFIA MODERNA Y CONTEMPORANEA}

Colmenares, Germán, "Factores de la vida política colonial",Nueva Historia de Colombia, Bogotá, Planeta Editorial Colombiana, Vol I, 1989.

De Souza Araujo, H. C, A lepra: estudos realizados na 50 paizes. 1924-1927, Río de Janeiro, Tip. de Osvaldo Ruiz, 1929.

Fischer, John R., "The effects oí comercio libre on the economies of New Granada and Peru: a comparison", 45 Congreso Internacional de Americanistas, Bogotá, Uniandes, 1988.

Jaramillo, Luis y Luis Cuervo, La configuración del espacio regional en Colombia, Santafé de Bogotá, CEDE, Universidad de los Andes, 1987.

Jaramillo Uribe, Jaime, "La administración colonial", Nueva Historia de Colombia, Bogotá, Planeta Editorial Colombiana, Vol. I, 1989.

Juan, Jorge y Antonio de Ulloa, Relación histórica del viaje a la América Meridional hecho de orden de S. M. para medir algunos grados del meridiano terrestre. 1748, Compilación efectuada por Eduardo Gutiérrez de Piñeres, Documentos para la historia del departamento de Bolívar, Cartagena, Tipografía de Antonio Arango, 1889.

Konig, Hans Joachim, En el camino hacia la nación, Santafé de Bogotá, Colección Bibliográfica Banco de la República, 1994.

Kuethe, Alian i., Reforma militar y sociedad en la Nueva Granada. 1773-1808, Santafé de Bogotá, Colección Bibliográfica del Banco de la República, 1993.

Kuethe, Alian J., "The early reforms of Charles III in the New Granada", 45 Congreso Internacional de Americanistas, Bogotá, Uniandes, 1988. 
Lemaitre, Eduardo, Historia General de Cartagena, Santafé de Bogotá, Banco de la República. T. II, 1983.

Martínez Carreño, Aida, (Editora), Pueblos de Santander. Procesos de desarrollo urbano. Bucaramanga, Teipel - Universidad Industrial de Santander, 1996.

Mc Farlane, Anthony, Colombia antes de la Independencia. Economía sociedad y política bajo el dominio Borbón, Santafé de Bogotá, Banco de la República - Ancora Editores, 1997.

Monsalve Martínez, Manuel, Libro de Actas del Muy Ilustre Cabildo y Regimiento de la Villa de Medellín, Medellin, Imprenta Oficial, 1911.

Montoya y Flórez, Juan Bautista, Contribución al estudio de la lepra en Colombia, Medellín, Imprenta Editorial, 1910.

Moreno y Escandón, Francisco Antonio, Indios y mestizos de la Nueva Granada a fínales del siglo XV]11, prólogo de Jorge Orlando Melo, Santafé de Bogotá, Biblioteca del Banco Popular, 1985.

Morales Muñoz, Tomás, Mario Bernal y H. C. de Souza Araujo, "Lazareto de Caño de Loro", Encuestas Epidemiológicas, Bogotá, 1940.

Obregón Torres, Diana, Struggling against leprosy. Physicians, medicine and society in Colombia. 1880-1940, Virginia Polytechnic Institute and State University, 1997.

Obregón Torres, Diana, "Lepra, de 'árbol maldito' a 'enfermedad curable'. Exageración y autoridad médica". Ponencia presentada en el 10 Congreso de Historia de Colombia. Medellín, 1997. Sin publicar.

Obregón Torres, Diana, "Los médicos y la construcción de la lepra en Colombia. 1884-1939"*. Salud, sociedad y cultura en América Latina. Nuevas perspectivas históricas, Lima, Instituto de Estudios Peruanos, 1996.

Obregón Torres, Diana, "Medicalización de la lepra, una estrategia nacional", Anuario Colombiano de Historia Social y de la Cultura, No. 24, Santafé de Bogotá, 1997.

Pinto Escobar, Polidoro y Santiago Díaz Piedrahita, José Celestino Mutis. 1732-J808, Santafé de Bogotá, Universidad Nacional, 1983.

Rodríguez Plata, Horacio, "Origen de la lepra en la antigua Provincia del Socorro", Boletín de Historia y Antiguedades, Bogotá, Nos. 751-754,1987. 


\section{TRATAMIENTO DE LA LEPRA EN EL SIGLO XVIII}

Sevilla Casas, Elias, Los mutilados del oprobio. Estudios sobre la lepra en una región endémica de Colombia, Santafé de Bogotá, Colcultura, 1995.

Silva, Renán, "La enfermedad de Hansen y la elefancía", Cali, Centro Universitario de Ciencias Sociales y Salud CEUCSA, Universidad del Valle, 1992. Texto sin publicar.

Twinam, Ann, "Las reformas sociales de los Borbones: una interpretación revisionista", Ponencia presentada en el Congreso de Historia, Medellín, 1997.

Urueta, José P, (Compilador). Documentos para la historia de Cartagena, Cartagena, Edición oficial, Tipografía de Antonio Araujo L. a cargo de O'Byrne, Tomo II 1888. 